Journal of Agriculture, Food and Environment (JAFE)

Journal Homepage: http://journal.safebd.org/index.php/jafe

http://doi.org/10.47440/JAFE.2021.2302

Original Article

\title{
Management practices for major insect pests of tomato by using insecticide treated nets and their impact on natural enemies
}

\author{
R. Amin ${ }^{1}$, M. E. Hossain ${ }^{1 *}$, R. Sultana ${ }^{2}$, M. A. Alam ${ }^{3}$, M. A. Hossain ${ }^{4}$ \\ ${ }^{1}$ Department of Entomology, Sher-e-Bangla Agricultural University, Bangladesh \\ ${ }^{2}$ Department of Horticulture, Sher-e-Bangla Agricultural University, Bangladesh \\ ${ }^{3}$ Department of Soil Science, Sher-e-Bangla Agricultural University, Bangladesh \\ ${ }^{4}$ Department of Agricultural Chemistry, Sher-e-Bangla Agricultural University, Bangladesh
}

\author{
Article History \\ Received: 5 July 2021 \\ Revised: 2 September 2021 \\ Accepted: 6 September 2021 \\ Published online: 30 September 2021

\section{*Corresponding Author} \\ M. E. Hossain, E-mail: \\ emam72@sau.edu.bd

\section{$\underline{\text { Keywords }}$} \\ Treated nets, Untreated nets, Natural \\ enemies, Integrated pest management, \\ Organic vegetable
}

\begin{abstract}
A B S T R A C T
In many parts of the world, insect pests are a serious problem in tomato production. In tropical countries, the utilization of pest exclusive nets to protect garden crops has proven to be an effective and sustainable tool against lepidopteran insects, but not against small insects. This study evaluated the repellent effect of a 40-mesh net with a diameter of $0.9 \mathrm{~mm}$ treated with cypermethrin against major tomato pests (including small sucking insects). The study was conducted at the experimental farm of Sher-e-Bangla Agricultural University, Dhaka to evaluate the management practices of tomato pests using insecticide treated nets and its impact on natural enemies. BARI Tomato-1 (Manik) variety was used as the planting material. The insecticide treated nets and non-treated nets were used as treatments with a control plot without any netting. The efficacy of insecticide-treated and untreated nets was evaluated over a period of six months. In this experiment, the treatments were replicated 3 times in a completely randomized block design. The evaluation of the abundance of major insect pests and their natural enemies in tomato was carried out by collecting and counting their numbers every week for each replication. Mature tomatoes were harvested after twelve weeks of transplantation, sorted and divided into marketable and non-marketable fruits. The total number of saleable fruits and their weights were recorded. A total of 7 pest species (Aphis gossypii, Thrips tabaci, Bemisia tabaci, Haltica pyritosa, Helicoverpa armigera, Tetranychus spp. and Liriomyza trifolii) those infected tomato plants during field production were identified. The insecticides-treated nets were fruitful in protecting tomato plants from A. gossypii, B. tabaci, T. tabaci, L. trifolii and $H$. armigera. Compared with tomatoes harvested from unprotected tomatoes, the average marketable fruit weight of tomatoes harvested using treated nets was significantly higher. The results of this study reveal the potential of using insecticides-treated nets as a viable strategy to increase tomato yields by reducing the number of pests in crops. The netting covers can be used as an integral part of the integrated management of insect pests in tomato production.
\end{abstract}

(C) 2021 The Authors. Published by Society of Agriculture, Food and Environment (SAFE). This is an Open Access article distributed under the terms of the Creative Commons Attribution 4.0 License (http://creativecommons.org/licenses/by/4.0)

\section{Introduction}

Tomato (Solanum lycopersicum L.) is an important economic crop of the Solanaceae family. The main tomato producing countries are China, the United States of America, India, Turkey, Egypt, Italy, Iran, Spain, Brazil and Mexico (Desneux et al., 2011). The world annual production of tomato in 2019 was $180.64 \mathrm{M}$ mt (FAO, 2020). Tomatoes are a popular vegetable in Bangladesh and are grown in open fields or in the highlands for home consumption, the fresh market, export and processing. Despite the economic benefits, farmers in Bangladesh still face many restrictions in the production process. Among these restrictions, arthropod pests and diseases are important (Waiganjo et al., 2006). Tomato production faces many constraints in its value chain, 
including low-quality seeds, various diseases and insect pests, low crop yields and post-harvest losses (Varela et al., 2003). Pests are one of the most important restrictions on tomato production. According to Lange and Bronson (1981), it is reported that 100 to 200 pests worldwide attack tomatoes. Insects attack tomatoes from the seedling stage to the harvest stage. The main arthropod pests include spider mites (Tetranychus spp., Acari: Tetranychidae), cutworms (Agrotis spp., Lepidoptera: Noctuidae), thrips (Thrips tabaci Lindeman and Frankliniella occidentalis Pergade, (Thysanoptera: Thripidae), whiteflies (Bemisia tabaci Gennadius, Hemiptera: Aleyrodidae). The main soil pests that attack tomato seedlings are cutworms, Agrotis spp., (Lepidoptera: Noctuidae), which cause damage by cutting the plants below the soil surface and causes the plants falling off. Chafer grubs, Schizonycha spp., (Coleoptera: Scarabaeidae) feeds on root portion (Waiganjo et al., 2006). Foliar pests including aphids, cotton aphids, thrips and whiteflies suck plant sap, causing leaf deformation and tomato growth retardation (Waiganjo et al., 2006).

Integrated Pest Management (IPM) is a method that can reduce counterproductive pesticide applications (Wheeler, 2002).This method is an ecosystem-based strategy that focuses on combining cultural, chemical, biological, and mechanical control to manage the level of insect pest population below the level that causes economic losses, thereby preventing pest damage to crops in the long term (Flint, 2012).Biological control agents are naturally occurring organisms those are capable of playing an important role in suppressing pest populations. These organisms can be local or imported. The utilization of these biological control agents can prevent environmental risks associated with chemical pesticides, while protecting crops in a sustainable way, because these organisms will not cause any non-objective harmful effects (Islam et al., 2020). The utilization of multiple management approaches can reduce dependence on pesticides, thus minimizing the emergence of pesticides resistance by pests (Raini et al., 2005). Synthetic chemical pesticides possess a fatalistic impact on producers, consumers as well as the environment (Pimentel and Greiner, 1997). According to Gitonga et al. (2010), dimethoate, abamectin, imidacloprid, cypermethrin and cyfluthrin are the extensively used pesticides in vegetable production systems. The demand for high-quality tomato fruits is a factor, and the utilization of synthetic chemical pesticides tends to increase to manage pests and diseases below the acceptable level of the tomato agroecosystem (Hamilton and Toffolon, 1987). According to Pimentel and Greiner (1997), most small vegetable producers rely on synthetic pesticide spraying for the reduction of insect pests damage, leading to pest resistance, pest reappearance, and pest development. secondary and the elimination of biocontrol agents. There are reports that tomato pests are returning as a result of the extensive utilization of insecticides across the world. In physical control methods, the idea is the use of different materials such as wood, metal, plastic, or other biological materials to build barriers for the purpose of protecting plants from insects throughout the season (from emergence to after harvest) (Vincent et al., 2003).

A potential way to break the dependency on pesticides is to use fine mesh nets as a part of the IPM approach (Vidogbéna et al., 2015). Deltamethrin-treated nets tested against diamondback moth (Plutella xylostella L., Lepidoptera: Plutellidae) and cabbage aphids (Lipaphis erysimi Kaltenbach, Homoptera: Aphididae) is effective in Benin,
China and Netherlands (Berlinger et al., 2002; Martin et al., 2006; Licciardi et al., 2008).

Insect net indirectly controls the flying insect pests of vegetable crops by establishing a mechanical barrier among the crops and pests (Vincent et al., 2003; Boiteau and Vernon 2004), thus reduces the need for pesticide spraying (Martin et al., 2006; Licciardi et al., 2008; Weintraub 2009). Latest findings on the effectiveness of mosquito nets against Bemisia tabaci (Wang et al., 2018) opened a window for exploring the utilization of low-cost mosquito nets for pest control in management of invasive pests by small farmers. Other advantages of this method include microclimate regulation, that ultimately increases crop yields (Briassoulis et al., 2007). However, the prospect of using nets in plastic tunnels in controlling tomato pests has received little attention. Therefore, this study aimed to test the efficacy of pesticide-treated nets for the management of tomato pests and their effect on natural enemies and increasing tomato production.

\section{Materials and Methods}

The experimental field is from Sher-e-Bangla Agricultural University, Sher-e-Bangla Nagar, Dhaka, Bangladesh study was conducted from September 2019 to June 2020. The experimental design was Randomized Complete Block Design (RCBD) maintaining $3 \mathrm{~m} \times 2 \mathrm{~m}$ plot size with $1 \mathrm{~m}$ block to block, $0.75 \mathrm{~m}$ plot to plot distance as well as $1 \mathrm{~m} \times$ $60 \mathrm{~cm}$ plant spacing. The experiment consisted of three treatments each of which had been repeated for three times. The 45 days old seedlings from the seed bed were transplanted in the main field on third week of October, 2019. The application method of Urea was top dressing in 3 equal installments at 20,40 and 60 days after transplanting (DAT) of seedlings. The three selected treatments of the experiment evaluated against pests in the tomato field were insecticide (Cypermethrin) treated insect proof nets $(0.9-\mathrm{mm}$ pore diameter and 40-mesh size), non-treated insect proof nets and control. The nets were cut into $1 \times 2 \times 0.75 \mathrm{~m}$ covers to protect the plants in the field after transplanting. Intercultural operations such as weeding, gap filling, irrigation etc. were done as and when required for ensuring and maintaining the normal growth of crops. The treatments were applied in the pre-designed plots which was continued till the last harvest of the fruits. The collection of data was started just before the first application of each treatment. The collected insects were identified with the taxonomic literature, expert scientists and university teachers. The collected data were statistically analyzed using the Statistix10 computer package to find out the variation among the treatment by F-test. Mean values of different treatments were ranked and compared for level of significance by Least Significant Difference (LSD) Test at 5\% probability.

\section{Results and Discussion}

Effect of management practices on the diversity and abundance of tomato pests in the field conditions

A total of seven pest species, A. gossypii, T. tabaci, B. tabaci, $H$. pyritosa, $H$. armigera, Tetranychus spp., and $L$. trifolii, were found in the tomato fields after transplanting. Tomato plants those were grown without any net covering (untreated control) had the highest numbers of pests 4,278 individuals were collected followed by untreated nets $(n=$ $3288)$ and treated nets $(n=2603)$ respectively (Table 1$)$. This was followed by seven species (A. gossypii, T. tabaci, B. tabaci, H. pyritosa, H. armigera, Tetranychus spp., and $L$. 
trifolii) observed higher on the non-protected tomato plants in. Tomato plants covered with insecticides treated nets and untreated nets study site had the least number of species observed with seven pest species identified (A. gossypii, $T$. tabaci, B. tabaci, H. pyritosa, H. armigera, Tetranychus spp. and L. trifolii.).

Table 1. Abundance of tomato pests among different treatments at field experimental sites.

\begin{tabular}{lccc}
\hline \multirow{2}{*}{ Pest species } & \multicolumn{3}{c}{ Treatments } \\
\cline { 2 - 4 } & No net & Treated net & Untreated net \\
\hline A. gossypii & $436.67 \mathrm{a}$ & $23.00 \mathrm{e}$ & $46.33 \mathrm{e}$ \\
T. tabaci & $205.00 \mathrm{~d}$ & $529.33 \mathrm{a}$ & $726.67 \mathrm{a}$ \\
B. tabaci & $360.00 \mathrm{c}$ & $53.33 \mathrm{~d}$ & $47.67 \mathrm{~d}$ \\
H. pyritosa & $2.33 \mathrm{~g}$ & $4.67 \mathrm{~g}$ & $3.67 \mathrm{f}$ \\
H. armigera & $4.67 \mathrm{f}$ & $7.67 \mathrm{f}$ & $3.00 \mathrm{~g}$ \\
Tetranychus & $6.33 \mathrm{e}$ & $190.67 \mathrm{~b}$ & $206.67 \mathrm{~b}$ \\
spp. & $366.67 \mathrm{~b}$ & $72.00 \mathrm{c}$ & $101.67 \mathrm{c}$ \\
L. trifolii & 0.18 & 0.28 & 0.18 \\
CV (\%) & 0.63 & 0.63 & 0.53 \\
LSD $(0.05)$ & & &
\end{tabular}

[In column, the treatment means with same letters indicate the statistically similar at $5 \%$ level of significance]

Among the insect pests of tomato observed in field condition, A. gossypii was the most dominant in many treatments (Table 1). Higher A. gossypii numbers were recorded in the control (436.67) of total collection. Though A. gossypii largely dominated the communities in different treatments but $T$. tabaci also was the most dominant pest in field condition. It constituted (726.67) and (529.33) of the total collection in tomatoes grown under untreated nets and treated nets respectively. Bemisia tabaci numbers were higher in non-protected tomato plants (360.00) compared to protected tomato plants. Generally, lower numbers of $B$. tabaci were observed on tomatoes grown under netting covers, where (53.33) and (47.67) were recorded under insecticides treated nets and untreated nets. Similarly, the occurrence of $L$. trifolii were higher in the non-protected tomato plants (366.67) compared to lower numbers of $L$. trifolii were recorded on tomatoes grown under netting covers, where (101.67) and (72.00) were recorded under untreated nets and insecticides treated nets respectively. This result was in the line with Bhusal et al. (2019) where they recorded lower insect pest infestation from the plots treated with Pest Exclusion Net (PEN) and the infestation was higher in untreated control plots. From the above findings it revealed that insecticides treated nets performed as the best treatment in terms of reducing the pest infestation of tomatoes compared no net.

Effect of management practices on abundance of natural enemies in the field conditions

Table 2. Abundance of natural enemies on tomato plants in the field.

\begin{tabular}{lccc}
\hline \multirow{2}{*}{ Natural enemies } & \multicolumn{3}{c}{ Treatments } \\
\cline { 2 - 4 } & No net & Treated net & Untreated net \\
\hline Aphidius spp. & $31.67 \mathrm{~b}$ & $7.50 \mathrm{~b}$ & $13.33 \mathrm{~b}$ \\
Predatory spiders & $40.67 \mathrm{a}$ & $9.33 \mathrm{a}$ & $16.67 \mathrm{a}$ \\
Other arthropods & $16.67 \mathrm{c}$ & $2.67 \mathrm{c}$ & $1.13 \mathrm{c}$ \\
CV $(\%)$ & 10.53 & 6.28 & 5.05 \\
LSD $_{(0.05)}$ & 1.33 & 0.93 & 1.19 \\
\hline
\end{tabular}

[In column, the treatment means with same letters indicate the statistically similar at $5 \%$ level of significance]
Significant variations were observed among different management practices in case of natural enemies through visual count during the management practices of tomato pests in the field (Table 2). The highest number of field spider was recorded in (40.67) comprising no net which was statistically different from all other treatments. Aphidius spp. (Hymenoptera: Braconidae) which parasitized aphid eggs and other arthropods as natural enemies also recorded higher in number (31.67) and (16.67) comprising no net.

On the contrary, the lowest number of field spider (9.33), Aphidius spp. (7.50) and other arthropods (2.67) through visual count was recorded in insecticides treated net management. More or less similar trends of field spider, Aphidius spp. and other arthropods population were also observed in case of untreated net management.

\section{Effects of insecticide treated nets on tomato yield}

Significant variations among different management practices were observed in terms of the number of fruits per plant during the management practices of tomato pests across the entire cropping season (Table 3). The highest number of fruits per plant (41.67) was recorded in the insecticides treated net which was statistically different from all other treatments followed by untreated net (37.33). On the contrary, the lowest number of fruits per plant (23.33) were recorded in the no net management practices of tomatoes in the field which was statistically different from insecticides treated net and untreated net management practices. More or less similar trends of results were also observed among different practices at number of marketable fruits and nonmarketable fruits per plant. This result was more or less similar with the findings of Bhusal et al. (2019) where they stated that the average yield of saleable tomato fruits recorded in plots under PEN was higher than those were grown without PEN (control). Gogo et al. (2012) reported that microclimate conditions in PEN generally promote seedling growth and, when combined with pest control, yields are higher (Muleke) et al. (2013) and Kiptoo et al. (2015).

From these findings it was revealed that insecticides treated net performed as the best management practice in terms of increasing the number of fruits per plant during the management of tomato pests in field. This was notably higher than untreated nets and no nets management practices.

Table 3. The mean numbers of total fruits, marketable fruits and non-marketable fruits harvested at field during different management practices on tomatoes.

\begin{tabular}{lccc}
\hline Treatments & \multicolumn{3}{c}{ Mean } \\
\cline { 2 - 4 } & $\begin{array}{c}\text { Total } \\
\text { number of } \\
\text { fruits } \\
\text { plant }^{-1}\end{array}$ & $\begin{array}{c}\text { Number of } \\
\text { marketable } \\
\text { fruits plant }^{-1}\end{array}$ & $\begin{array}{c}\text { Number of } \\
\text { non- } \\
\text { marketable } \\
\text { fruits plant }^{-1}\end{array}$ \\
\hline No net & $23.33 \mathrm{c}$ & $13.67 \mathrm{c}$ & $10.33 \mathrm{c}$ \\
Untreated net & $37.33 \mathrm{~b}$ & $20.33 \mathrm{~b}$ & $19.33 \mathrm{~b}$ \\
Treated net & $41.67 \mathrm{a}$ & $23.33 \mathrm{a}$ & $21.67 \mathrm{a}$ \\
CV \% & 7.58 & 7.52 & 6.98 \\
LSD $(0.05)$ & 1.19 & 1.04 & 1.09 \\
\hline
\end{tabular}

[In column, the treatment means with same letters indicate the statistically similar at $5 \%$ level of significance] 


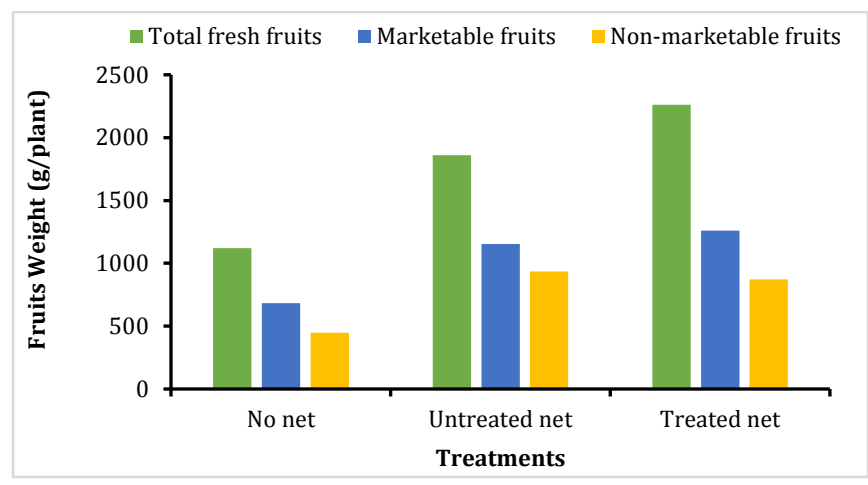

Figure 1. The mean weight of total fruits, marketable fruits and non-marketable fruits harvested at field during different management practices on tomatoes.

There were variations in the mean total fresh weight of tomatoes harvested among the treatments (Figure 1). There were also differences in the mean marketable fruit weight and non-marketable fruits weight among the treatments. The highest mean weight of total fresh fruits was observed in insecticides treated nets (2260.9) followed by untreated nets (1861.0), while the least weight of total fresh fruits was harvested in control (no nets) (1118.7). More or less similar trends of results were also observed among different practices at weight of marketable fruits and non- marketable fruits per plant.

From these findings it was revealed that insecticides treated net performed as the best management practice in increasing the weight of fruits per plant during the management practices of tomato pests in field. This was notably higher than untreated nets and no nets management practices.

\section{Conclusion}

Insecticides treated nets with a cover mesh diameter was effective in protecting tomato plants against major pests especially A. gossypii, B. tabaci and $H$. armigera. The application of insecticide treated nets was less effective in protecting tomato plants against $T$. tabaci and Tetranychus spp. The netting covers, either treated with insecticides or untreated, allowed an opportunity for entry of natural enemies inside the netting covers when performing agronomic operations such as weeding, watering and fertilizer application hence could be used effectively in an integrated pest management strategy. Insecticides treated nets believed to be considered as a viable strategy for enhanced tomato production through reduction of insect pests population.

\section{References}

Berlinger MJ, Taylor RAJ, Lebiush-Mordechai S, Shalhevet S, Spharim I (2002). Efficiency of insect exclusion screens for preventing whitefly transmission of tomato yellow leaf curl virus of tomatoes in Israel. Bull Entomol Res 92: 367-373.

Bhusal K, Sagar GC, Bhattarai K (2019). Use of Low-Cost Pest Exclusion Net to Control Tuta absoluta Infestation and Boost the Yield of Tomato in Surkhet and Dang Districts of Nepal. World Res J of Agril Sci 6(2): 162166.

Boiteau G, Vernon RS. (2004). Physical barriers for the control of insect pests, In: Horowitz AR, Ishaaya I, editors. Insect pest management. Berlin: Springer. : 224247.
Briassoulis D, Mistriotis A, Eleftherakis D (2007). Mechanical behavior and properties of agricultural nets Part I: Testing methods for agricultural nets. Polym. Test. 26: 822-832.

Desneux N, Luna MG, Guillemaud T, Urbaneja A (2011). The invasive South American tomato pinworm, Tuta absoluta, continues to spread in Afro-Eurasia and beyond: the new threat to tomato world production. J Pest Sci 84: 403-408.

FAO (2020). Production year book. 54, FAO. Italy

Flint ML (2012). Integrated Pest Management in Practice: Principles and methods of Integrated Pest Management. $2^{\text {nd }}$ edition. University of California Agriculture and Natural resources, USA. pp.2.

Gitonga ZM, Chabi-Olaye A, Mithöfer D, Okello JJ, Ritho CN (2010). Control of invasive Liriomyza leafminer species and compliance with food safety standards by small scale snow pea farmers in Kenya. J Crop Prot 29: 1472-1477.

Gogo EO, Saidi M, Itulya FM, Martin T, Ngouajio M. (2012). Microclimate and modification using eco-friendly nets for high quality tomato transplant production by small scale farmers in East Africa. Hort Tech 22: 292298.

Gomez KA, Gomez AA (1984). Statistical procedures for Agricultural Research. Second Edition. A Wiley Interscience Publication Jhon Wiley and Sons, New York, Chichester, Torento, Singapore. p.680.

Hamilton JT, Toffolon RB (1987). Pests of tomatoes. Agfacts, Department of agriculture, New South Wales. pp.19.

Islam MN, Islam KS, Jahan M, \& Rahman MS (2020). Investigation on the Natural Enemies of Jute Yellow Mite and Their Performances and Seasonal Incidence. Agricultural Science, 2(1), 56-69.

Kiptoo J, Kasina M, Wanjala F, Kipyab F, Wasilwa LA, Ngouajio M, Martin T (2015). Use of low-cost pest exclusion nets can boost cabbage yield. E Afr Agr Forestry J 81: 112-11

Lange WH, Bronson L (1981). Insect pests of tomatoes. Annu Rev Entomol 26: 345-371.

Martin T, Assogba Komlan F, Houndete T, Hougard JM, Chandre F (2006). Efficacy of mosquito netting for sustainable small holders' cabbage production in Africa. J Econ Entomol 99: 450-454.

Martin T, Chandre F, Ochou G, Vaissayre M, Fournier D (2002). Pyrethroid resistance mechanisms in Cotton Bollworm Helicoverpa armigera (Lepidoptera: Noctuidae) from West Africa. Pestic Biochem Phys 74: 17-26.

Martin T, Palix R, Kamal A, Deletre E, Bonafos R, Simon S, Ngouajio M (2013). A repellent treated netting as a new technology for protecting vegetable crops. J Econ Entomol 106: 1699 - 1706.

Muleke EM, Saidi M, Itulya FM, Martin T, Ngouajio M (2013). The assessment of the use of eco-friendly nets to ensure sustainable cabbage seedling production in Africa. Agronomy 3:1 -12 .

Otoidobiga LC, Vincent C, Stewart RK (2002). Susceptibility of field populations of adult Bemisia tabaci Gennadius (Homoptera: Aleyrodidae) and Eretmocerus sp. (Hymenoptera: Aphelinidae) to cotton insecticides in Burkina Faso (West Africa). Pest Manag Sci 59: 97-106. 
Pimentel D, Greiner A (1997). Environmental and socioeconomic costs of pesticide use. In: Techniques for Reducing Pesticides: Environmental and Economic Benefits (Pimentel D Eds.), John Wiley and Sons, UK, pp 51-78.

Raini R, Hoffmann V, Zebitz CPW (2005). Integrated Pest Management (IPM) and information flow: case study, tomato stakeholders' practices in Kenya. Paper presented to the conference Deutscher Tropentag 11-13 October 2005, Stuttgart-Hohenheim.

Varela AM, Serf A, Lohr B (2003). A guide to IPM in tomato production in eastern and southern Africa. International Centre of Insect Physiology and Ecology, ISBN 9290641495.

Vidogbéna F, Adégbidi A, Tossou R, Assogba-Komlan F, Ngouajio M, Martin T, Zander KK (2015). Control of vegetable pests in Benin-Farmers' preferences for ecofriendly nets as an alternative to insecticides. J Environ Manage 147: 95-107.
Vincent C, Hallman G, Panneton B, Fleurat-Lessard F (2003). Management of Agricultural Insects with Physical Control Methods. Annu Rev Entomol 48: 261281.

Waiganjo MM, Wabule NM, Nyongesa D, Kibaki JM, Onyango I, Wepukhulu SB, Muthoka NM (2006). Tomato production in Kirinyaga district, Kenya. A baseline Survey report. pp. 3-4.

Wang F, Liu J, Dong Y, Chen P, Zhu X, Liu Y, Ma J (2018). Insect-proof netting technique: Effective control of Bemisia tabaci and Tomato chlorosis virus (ToCV) in protected cultivations in China. Chil J Agric Res 78(1): 48-58.

Weintraub P. (2009). Physical control: an important tool in pest management programs. In: Isahaaya I, Horowitz AR, editors. Biorational control of arthropod pests. Netherlands: Springer:317-32.

Wheeler WB (Ed.) (2002). Pesticides in Agriculture and the Environment. CRC Press. 